\title{
A Critical Investigation on the Impact of Employee's Engagement on Employee's Productivity at the Ministry of Commerce and Industry-Oman
}

\author{
Haitham Mohammed Al- \\ Maamari \\ Dr. Maria Teresa Matriano \\ Middle East College \\ Middle East College
}

\begin{abstract}
The theory of employee engagement is part of human resources management nowadays as it is a key to the success of companies around the world. Innovative institutions seek to understand the employees to increase their engagement, job satisfaction, and productivity that lead to more profitability for company. This study is about the critical investigation on the impact of employee's engagement to employee's productivity in the Ministry of Commerce and Industry (MOCI)-Oman. This study has applied the descriptive research design using both qualitative and quantitative methods. Managers and employees in the Ministry were interviewed to understand in depth the impression of employees about their engagement in the Ministry. The results revealed that most of the employees are not engaged at MOCI. The recommendation aimed at providing an effective employee engagement framework for the ministry's culture that suits the nature of the employees. This study can be used as well by other government sectors that follow the same approach as the Ministry of Trade and Industry (MOCI) to increase the overall level of employee engagement.
\end{abstract}

\section{Introduction}

This chapter is a preliminary introduction to what the research will be. The purpose of this research is to assess the environment and culture of employee's engagement in the Ministry of Commerce and Industry. The research objective, scope, and significance of the study are going to discuss to reach a framework that fits the nature of the Ministry's working mechanism. The purpose of this study is to investigate on employee's engagement in the Ministry of Commerce and Industry and its impact on employee's productivity.

The employee's engagement became popular in this millennium although it appeared in the early 1990s, it also appeared as work engagement and is now defined by the relationship of employees with his work, and with the company (Bakker, A.B. and Leiter, M.P., 2015).

The employee's engagement has several factors, the most important of which are satisfaction, motivation, and effectiveness. If the working environment lacks these factors, it leads to a decrease in productivity. The strength of the organization is managed by managing staff participation, which increases performance and profitability results. High engagement levels are linked to a group of useful results, including a high level of performance (Georgiades, S., 2015).

The research investigation is in the Ministry of Commerce and Industry in the Sultanate of Oman, and the main reason for choosing a government entity for this study is that ministries operate with traditional management where the employee's participation, ideas, and decision making is almost non-existent.

The harmony and integration between the staff and the working environment make the employee 
introduce innovation. Global companies in the modern millennium such as Microsoft and Samsung have a high index of employee engagement, which has positively impacted on innovation and profitability.

The main objective of the dissertation is to understand the employee's engagement of this government institution and how to make a suitable environment for engagement. The researcher focuses on the staff in the main building of the Ministry in Muscat, with the e-form to be distributed to selected employees from administrative, and technical jobs; and to the managers and head sections of the following Directorates (Directorate General of Planning, Directorate General of Commerce, Directorate General of Industry, Directorate General of Administration and Financial Affairs, Directorate General of Organizations and Commercial Relations and Directorate General of Development of Small and Medium Enterprises).

Moreover, all scientific materials related to the employee's participation will be studied to understand the key aspects of success on employee's engagement. An investigation as well on different frameworks, both local and global, will be considered to propose a new framework for MOCI.

\section{Aim and Objectives of the Study}

This study aims to understand the employee's engagement in the Ministry of Commerce and Industry to design an effective framework that is suitable for the work environment of MOCI. The study initially focusses on measuring staff participation in their working environment and the factors that affect their productivity; and on information technology that helps improve engagement among employees. Likewise, the study is to recommend a framework of employee engagement to the Ministry in order to increase the productivity of employees towards achieving the goals of the Ministry.

\section{Research Objectives}

In the context of the investigation of employee's engagement and its effects on the productivity of the employee, the following objectives are considered for this research:

1. To investigate on the level of employee's engagement in the ministry.

2. To investigate the success factors of employee engagement in the ministry.

3. To investigate the impact of employee engagement on employee productivity.

4. To propose a new employee engagement framework for the ministry.

\section{Research Questions}

The investigation of the objectives of the study are to be through the following research questions:

1. What are the different levels of engagement of employees in the ministry?

2. What are the ministry's criteria for success factors on employee engagement?

3. What is the impact of employee's engagement on employee's productivity?

4. What most appropriate employee engagement framework can be proposed for the ministry.

\section{Significance of the Study}

The investigation of this research focuses on the impact of employee engagement and its effectiveness on productivity, as the Ministry of Commerce and Industry follows the traditional approach in management, which poses a great challenge and negatively affects the employee. Therefore, the research seeks to work on the framework and get results to raise the efficiency of 


\section{Journal of Student Research}

Fourth Middle East College Student Research Conference, Muscat, Sultanate of Oman

the employee, which benefits the ministry because the ministry is an essential engine of the country's economy. The implementation of a new policy of employee's involvement has positive effects at the level of the Ministry and the Sultanate. The results of the investigation will benefit a variety of parties as follows:

First, the Ministry of Higher Education reports that it provides the Ministry (MOHE) with an efficient framework for one of the Ministries of the civil service in order to strengthen its curriculum and to be one of the accredited sources of work frameworks for employee engagement in the ministries in Oman.

The results and analysis of this study will be a reference to the Ministry of Commerce and Industry to work a framework model that benefits the productivity of the employee. Moreover, this study will serve as a reference for future research that is interest in working an effective framework for career integration.

There are few studies in this field in Oman that will help university students to understand the working framework of employee's engagement by providing the best solutions around studying such topics and improving them. Furthermore, traditional employers will benefit from the working frameworks that will improve employee's productivity.

\section{Literature Review}

Employee's engagement implies that the employee shall demonstrate an unequivocal obligation towards the company and its targets. As such, this emotional obligation indicates that engaged employee is mainly concerned with their obligations and organization. They work to serve the company's objectives rather than to aim for having their paycheck or for having the next increment. So, when the employee participates and does their utmost, that means that they do care about this job.

According to Markos and Sridevi (2012), it was stated that:

"The main idea of any business management is what determines the extent to which the employee has reached in his passion and commitment towards his work. Participating employees are seriously concerned with their work and the earning of their company, and they feel that their efforts might make a difference."

The researcher is trying to highlight the use of employee engagement which is to create a level of keenness and devotion for employees so they can put extra effort since they are made to believe that their hard work can really make a difference.

Albrech (2011) has stated that:

Any evolving and working situation, such as just as any emotional, proactive, and constructive knowledge-based state aims mainly to the organizational results.

It seems to be that the author tries to refer to employee's engagement as a kind of employee`s situation which is positive perceptual and cooperative oriented towards organizational ultimate objectives to make a framework leading to more employee productivity.

It turned out that participating employees are dissatisfied with their salaries and promotion. Therefore, this definition has failed to clarify the techniques that can lead the employee to the state of devotion in their work, or even how to reach this state apart from their salary or promotion. 
According to Crawford, LePine, and Rich (2010):

Employee's engagement is a characteristic of the association between a business and its workforces. An "engaged employee" is one who is completely engrossed by and keen about their job and so takes constructive action to further the organization's status and welfares.

It seems to be that the author tries to indicate the characteristics of the participating employee, who is obviously a dedicated worker, able to make positive decisions, and is strongly committed to enhancing the company`s reputation and position through his devotion to his work to be more productive and beneficial to the ministry and the reviewers.

It is logical that man works to achieve his basic needs, such as, food, shelter, and clothing, rendering him to be loyal to the company that affords him these basic needs. This means that this definition requires more explanation to the close link that connects the employee to their company.

It can be summarized that employee engagement is simply a deceptive concept that can trigger employees to reach better performance. Thus, it enables employees to feel more empowered and have a good business ethic. All the previous definitions have failed to give us a clearer idea about how to reach the participative state or how to make employees participate. Since some definitions have focused more on the practical influence of managing the employees, whereas the other definitions have stated their benefits. However, none of these definitions have explained the techniques and tactics to provide the employees with such deceptive power. Thereby, none of these definitions can be reliable.

\section{Levels of Employee Engagement}

It's no secret that engaged employees are more industrious as compared to their disoriented peers. However, we're not precisely sure how best to engross staff. When determining which workers to engage, or how, keep two principles in mind. First, tactically, the biggest payoff is to be obtained by engaging those workers who can add most worth or who will be most powerfully driven by it. Secondly, no single engagement approach will work with all workers, so it is sane to experiment. (Albrech 2011) This study will discuss various levels of employees' engagement proposed by authors.

\section{Megan Wells Theory}

According to a data journalist, Megan Wells (2017), has stated three levels of employee's engagement as follows:

1. Engaged employees work passionately and feel deeply related to their company. They lead creativity in their company and take it forward. Though only 30 percent of the US workforce is classified as participating workers.

2. Not engaged employees are regarded as "redundant." They do their work effortlessly. They spend their time at work, but not their efforts or emotions.

3. Actively disengaged employees are more wretched at work. They make their morality clear to everyone, too. They compromise what their working mates do every day. About $17 \%$ of the US workforce is considered separate. (Wales 2019).

\section{Dhom Rheem Theory}

The former congressional science advisor, Dhom Rheem, has stated the levels of employee's engagement as follows: 
1. Highly-engaged workers are considered (A class) workers. They can transform the regular workplace into a modern, effective, and funny place. When workers work side by side with such co-workers who are compatible, predictive, and confident, they would be able to accomplish more than they do alone. They would have the same interest and deep ties to what their work and to whom they work for. Additionally, they would have more physical skills to deal with the huge and terrifying issues in their work. These "A class" workers can inspire others who are less involved in their work and can raise their level of engagement in a specific task or for the period through which they work together.

2. When we evaluate engagement in our customer organizations, the author calls these workers as actively engaged, and these workers cover from five to fifteen percent of the workforce in the premium companies.

3. In the same manner, nearly twenty to twenty-five percent of staff are engaged. They are engrossed in their duties and do genuine labor. Their attitude is optimistic, they work hard, and they usually have faith in the mission and idea. Several of them are enthused by the A+ workers they feel fortunate to be related with. Staff engaged at this level are the performance mainstay for any initiative.

4. In most institutions, employees account for almost $50 \%$ of what the author classifies as somewhat disengaged. They are lazy and usually do a satisfactory job, though they do not get close to their potential. There may be many reasons for that, and the most notable one has an ineffective principal. These fairly separate employees are subject to deviation for two to three hours each day, which disturbs the workflow and quality of collaborators who dislike their presence.

5. Traditionally, a small group of workers is considered actively disengaged, nearly five to fifteen percent of the workforce. They have withdrawn, however, they still want to earn money. These are the people who are strongly uncertain about the task and ideology. They have an aggressive attitude towards the company and its executives, and they do just enough not avoid being reproached or dismissed. The company imposes on them working for eight hours, but they actually work four hours only. However, even their work time is deviated from its main purpose, since all they do is undermined by what they prevent the others from accomplishing (Rheem 2019).

\title{
Mitch McCrimmon: has stated the levels of employee's engagement as follows:
}

\section{Level One: Basic Engagement}

\begin{abstract}
A basic level of engagement employs motivational features such as strong direction, good management, enablement, career expansion, unrestricted communication, credit, and producing a decent place to work. Such ingenuities all include doing something for workers, though, and are therefore authoritarian.
\end{abstract}

\section{Level Two: Employees as Suppliers of Services}

This level requires a culture that inspires workers to consider themselves when they run their own businesses, as service traders. Most administrative cultures are autocratic and have a lot of accountability for people who develop work. Workers need to learn how to present their superiors as clients and be trained to advertise their business and develop their own business properly. This business growth involves good knowledge of the important internal customer needs and has productive thinking in complementary ways to add quality to these products.

\section{Level Three Engaging Leadership}

Level three engagement needs a more profound culture transformation since it asks executives to 
basically reframe how they view their roles. It goes past level two engagement by inspiring executives to be more active in taking input from workers since it also puts more burden on workers to do more thinking and be less contented to simply follow instructions. Level three engagement involves shifting from gallant, transformational leadership to a more collaborative model of leadership, where bosses shift from being solution generating goal achievers to enablers, catalysts, and tutors.

\section{Level Four Engagement}

It shall be noted that this level involves cultural diversity. Now, regardless of viewing the worker's thoughts simply as adequate comments, their engagement is reconfigured as a progressive leadership. Thus, workers need to be more self-confident so as to they can confront their superiors, while executives need to be more open- minded being challenged. This move involves the engagement of workers by having a sense of solidarity and making room for the company, or even a simple part. The sense of leadership can result a more stable sense of ownership than it can propose. (McCrimmon 2019).

It can be assumed up that the importance of employee engagement cannot be overstated. That means that employee engagement directly affects the company's core outcome. Since companies may move across the different levels of staff engagement proposed by the above- mentioned authors, they gradually reduce the space between dependency and empowerment. Therefore, courageous and transitional leadership focuses on the intellectual sense of ownership at the top, as well as, it utilizes the dependency of anyone else (Grumman and Saks 2011). The distinction of progressive leadership can be detected go a long way in reconciling this power stability, making more common ownership and more consistent collective efforts to help companies to thrive. All the levels of employee engagement share a distinctive advantage: they all share the intelligence of employees and inspire them to think more about themselves and about the company.

\section{Success Factors of Employee Engagement}

It is evident that the relation between bosses and workers has experienced a massive shift. Certainly, senior managers have to devote more time bearing in mind the strategies needed not only to entice new staff, however, also to ensure their retainment. Every Tom, Dick, and Harry have job experiences that feel more like fun, and ones where they couldn't wait to get out, merely because they weren't devoted to the job or product. This is where employee engagement barges in. It motivates people to come on board. (Al Mehrzi and Singh 2016). This essay will discuss the different Employee engagement styles used by organizations and analyze how such employee engagement styles have benefited organizations in terms of productivity and performance.

\section{Employees Success Area}

It's a misconception that money is not the solution to get employee engagement. The employee does not feel motivated by their remuneration packages. According to a study by Professor William Kahn, he concludes that employees feel engaged when:

1. They feel that their work was constructive, and it actually made a difference.

2. They feel respected, reliable and treasured.

3. They feel secure and confident. (Ruck and Menara 2017).

Therefore, senior executives and bosses adopt such styles that inspire the above-mentioned sentiments into their employees so that they can be engaged.

\section{Thinking Bottom-up Strategy Style}


It is true that we cannot build a house starting from its roof. We have to make a ground first. It's the same case for companies. The employees of the companies are bedrock, on which the organization can be founded. So, surveying and taking feedbacks from employees is vital when evaluating our workers' feelings and sentiments. The more we ask our employees the question, the more, it will create a sense of empowerment in our employees. When these employees are empowered, reliable and valued, the more they will become engaged. (Chin et al. 2015)

- Show Your Employees That You 'Listen'

- Ensure that Your Employees are Heard

- Understanding Individual Learning Styles

If the manager is able to comprehend how his staff learns, whether they wish to work individualistically or in teams, for instance, the manager can find out a lot about how well they work and in which habits they are more probable to engage with work jobs. Managers also need to evaluate the probable time in which a certain employee can learn, and for how long it will take him to get proficient in his specific area of responsibility. (Gill 2015) This is a significant consideration with online training in specific: We can find out that some workers will happily get on with specific training, whereas others are better matched to synched, collective learning. There should be a Talent Development Platform in each organization that needs to accommodate a variety of behaviors in which the employee can engage with their training. (Sarti 2014)

\section{Sharing Good Practice and Exchanging Ideas Between Teams}

Managers and executives have far more experience of the jobs as compared to their employees as they have been at their stage, so they know the ground realities. Therefore, they need to share their experience and exchange ideas with their teams. In the same manner, let your employees have the opportunity to share and show their finest work. Meeting and sessions between seniors are a great way to invoke engagement and make or reinforce relations between your workers.

\section{The author is discussing the organizational outcomes of applying the strategies:}

- Higher Profits and Productivity

- Improved Quality

- Customer Loyalty

- Financial Success:

- Employee Performance

- Commitment and Motivation

\section{Impact of Employee Engagement on Productivity}

Engagement is a crucial matter for a hard-working employee because it costs alternative staff compared to maintaining and developing it. Most companies confirm the deadlines for their completion and work instead of focusing on the level of engagement of workers in their company. 
They tend to ignore that it is also important for workers to be enthusiastic about what they are doing. The involved worker can contribute a lot to structural efficiency compared to 10 unconnected workers. (Kumar and Pansari 2015), staff engagement can have an impact on our business. This article discusses the fact that employee engagement affects employee productivity and how it is used in companies and government sectors.

\section{Creative Work-Approach}

The monotonous missions lead to disengagement and decreased attention to the employee. When employers stress employee engagement and make the workflow challenging for workers, the employees deal with their office goals differently. Workers tend to use a new approach to achieve their goals.

\section{Improved Employee Retainment and Talent Attainment}

It is an acknowledged fact that the more a company concentrates on its workers' contentment and gratification, the more devoted the staff are to the organization.

\section{Karanges Theory}

According to the study, organizations with the greatest performers have three activities that take place:

1. They have periods of a decade or more in their institutions.

2. They indulge in their daily work.

3. They are playing the roles where the horizons work well to match their distinctive talents. Each variable affects results on its own; however, the maximum performance is derived from the mixture. (Karanges 2015)

When the company emphasizes employee engagement and gratification, it not only appeals to quality talent for business but also assists you in retaining current workers better.

Frameworks for Employee Engagement

As for modern companies, keeping employees involved is a constant battle. If employees are not connected and not involved in the work they are supposed to do, how can we assume that potential customers are excited about our business? Separated staff can separate complex rates of inattention, inefficiency, higher turnover, and greater space for human error, safety events, and much more. Therefore, the employee's employment contract changes. Persuasive CEOs are currently building institutions that involve employees as sensitive and motivated shareholders, such as in, Microsoft and Google. (Noe 2017) Workers today amplified negotiating power, the labor market is very transparent, and highly skilled and skilled employees represent a very competitive movement. Companies now benefit from analysis tools to find reasons why employees leave and why they leave, purpose matters, engagement, and culture assessment in the minds of corporate leaders throughout through many frameworks that benefited modern companies and traditional government sectors. (Albareda et 2012). This article discusses the engagement frameworks of employees employed in modern companies and governments that affect employee productivity and performance.

\section{Research Methodology}

In this research, the descriptive research design using interviews and quantitative research methods through survey questionnaire was used. The quantitative results were analysed in 
statistical forms by quantitative research analysis methods. Descriptive analytical methods of research have been extensively presented in order to obtain the desired results.

Descriptive statistics were used to determine the nature and degree of the relationship between the parties to be stated. The hypotheses were analysed using the SPSS (Statistical Package for Social Sciences). The same statistical tool was used to extract the following results, percentages, frequency, mode, median, mean and finally the correlation statistics between the independent variable and dependent variable.

The researcher used both the quantitative and qualitative data collection with the employees of MOCI. Quantitative data collection was through the survey questionnaire conducted with selected MOCI's employees. For the qualitative data collection, the researcher interviewed four head sections from four of different departments.

\section{Qualitative Research}

Qualitative research is principally the investigative research, used as a tool to understand the causes, opinions, and motives of the targeted people. It provides insights into the problem or helps develop ideas or hypotheses for potential quantitative research. There are several methods of collecting data used for this research, which include the focus group discussions, open questions for individual observations and interviews.

\section{Quantitative Research}

This quantitative research is used to determine the size of the problem by generating digital data or data that can be converted into usable statistics. It is used to identify specific positions, opinions, behaviors, and other variables - and generalize results from a larger set of samples. In addition, it is measurable to identify the challenges of the researcher and reveal the best patterns of investigation. Quantitative data collected is easier and more structured than collecting qualitative research data. There are many methods for collecting quantitative data: through meetings, telephone interviews, essay studies, and websites.

\section{Primary Data}

Primary data was collected through a questionnaire which was distributed electronically to the ministry. This questionnaire has introduction writing on the top of the questions and explaining the basic purpose of the research so that they respondents can understand the employee engagement theory and will answer the questionnaire correctly. The questionnaire form is sent to administrative employees and to those occupying the higher positions to different sections mentioned in chapter 1. Questions focused on the understanding of employee's engagement and how to improve engagement and whether information technology can be useful in increasing employee's engagement. Employees to target are the 200 administrative employees. Basis of this was done through the Cochran sampling technique.

\section{Questionnaire Design}

The questionnaire was divided into four parts in order to defeat the employees of the administrative category. The first part provided is to know the employee's data. Part 2 is the employee's engagement level. The third part is the success factors of employee's engagement, and the last part is the impact of employee's engagement on employee's productivity.

\section{Interview}


The researcher interviewed four Head Sections of different departments in the MOCI. The interviewees are the Head Section of Boards and Committees, Head Section of HR Development, Head Section of Anti-Dumping and H.S of Commercial Licences. The researcher was able to interview only four head sections due to summer vacation issue as the majority went on summer break. The interview questions consisted of three questions: -

1. Does the Ministry of Commerce and Industry have a clear approach and strategy for employee engagement?

2. Based on your work experience, what are the factors that are successful in increasing employee's engagement in the Ministry of Commerce and Industry?

3. Based on the semi-traditional work of the Ministry of Commerce and Industry, does the employee engagement increases employee productivity?

\section{Quantitative Methodology}

This is the methodology used for distribution to 200 employees using the survey questionnaire with the following components:

1. Employee's Demographic.

2. Engagement Level.

3. Engagement success factor.

4. Employee's Productivity.

The researcher used the SPSS program tool (Statistical Package for Social Sciences) and Excel sheet to analyse the results. These programs have the advantage of facilitating the analysis of the data and can produce statistical drawings in several forms and in a detailed way which helps to read the numbers from different angles.

\section{Secondary Data}

The researcher collected secondary data from several sources but has focused on trusted electronic libraries (Coventry Library, academia.edu, and ethos.bl.uk) to search for books, articles and scientific journals. Materials from the following libraries were considered as well: the libraries located in the Sultanate of Oman, including the Library of the Faculty of Middle Affairs and the Sultan Qaboos University College. In addition, the researcher explored at the websites known as Business Harvard Review.

\section{Data Collection}

Data collection is a set of structured and integrated steps that are used in the analysis of information provided by the researcher to reach good results. The steps and means vary depending on the nature of the research and its characteristics and the target group. Scientific research is based on a certain set of conditions, which is clear wording and formulation in correct ways.

\section{Data Analysis}

The researcher analyzed the data in this study based on statistical analyses to understand all aspects of the research objectives. Multiple descriptive, mean, and standard statistics are made to analyze the results in depth.

The nature and degree of graphics relationships are determined by Pearson's links (reward, motivation, and satisfaction). Data were analyzed using SPSS software (Statistical Package for Social Sciences) and the interview results by using Microsoft Excel. 


\section{Population and Sampling Size}

The population study of the investigation are all administrative employees in the following departments (Directorate General of Planning, Directorate General of Commerce, Directorate General of Industry, Directorate General of Administration and Financial Affairs, Directorate General of Organizations and Commercial Relations and Directorate General of Development of Small and Medium Enterprises) of MOCI employees in the main building. The ministry has 450 employees for these departments. From these departments, the researcher has targeted the administrative employees with at least one-year experience and those from the higher positions totaling to 200. Departments were selected on the basis of the importance of their jobs as administrators in interfering with decision making and their contributions to the transmission of ideas and proposals.

The sample size of the study is 132 employees (as computed below). From this 132-sampling size, the researcher has collected only 129 employees that are $97.7 \%$ retrieval rate.

Judgmental purposive sampling technique was used in this research. It is a non-probability sampling technique that helps the researcher to get results more accurate. The sample size was derived by calculating the minimum sample size required for accuracy in estimating ratios by looking at standard normal deviation set at 95\% confidence level of (1.96), percentage picking a choice or response $(50 \%=0.5)$ and the confidence interval $(0.05= \pm 5)$. The formula is: $\mathrm{N} 0=(\mathrm{z} 2 \mathrm{pq} / \mathrm{e} 2)$.

The researcher met the employees in the Human Resources Department to know what the initial valuation of the work environment is. With this, the questionnaire form was drafted to suit the ministry environment. Notes were taken and recorded regarding the employee's handling of the work procedures. This was an effective way to understand the mechanism for dealing with employees. Likewise, this aid as well in devising a framework on employee's engagement.

\section{Data Analysis}

\section{Quantitative Research Analysis}

The responses to questionnaire consisting of 12 questions that focused on research objectives were reviewed, and collected information were analyzed. The results of the respondents and information on the details of the respondents were analyzed using the quantitative research analysis. The objectives are to find out the level of engagement and what factors are contributing to the success of the engagement, as well as the effects of the engagement on employee's productivity. The questionnaires were distributed to the employees in the selected directorates in the main building of Muscat and were filled out by 129 employees.

\section{Qualitative Research Analysis}

The methodology of qualitative research was conducted through the interviews of four of the heads of the sections. Results were analyzed as well.

\section{Analysis Results}

Table 1.0 showed the percentage of employees age in the Ministry who participated in the survey. The percentage of age between 20 to 30 is the highest at $49.6 \%$. The second between 31-36 at 26.4 $\%$, 3rd at $20.7 \%$ for age between 36-44. The last group, the oldest age group is where it turns out that they are the lowest number in participation. The largest respondents are @age 20-30. This is because of the government's employment plan for the Government of Oman in previous years. The 
employment plan was only for fresh graduates who are young and employed only in positions from administrative and lower positions.

\section{Table 1.0 Status of Respondents}

Status

pondents

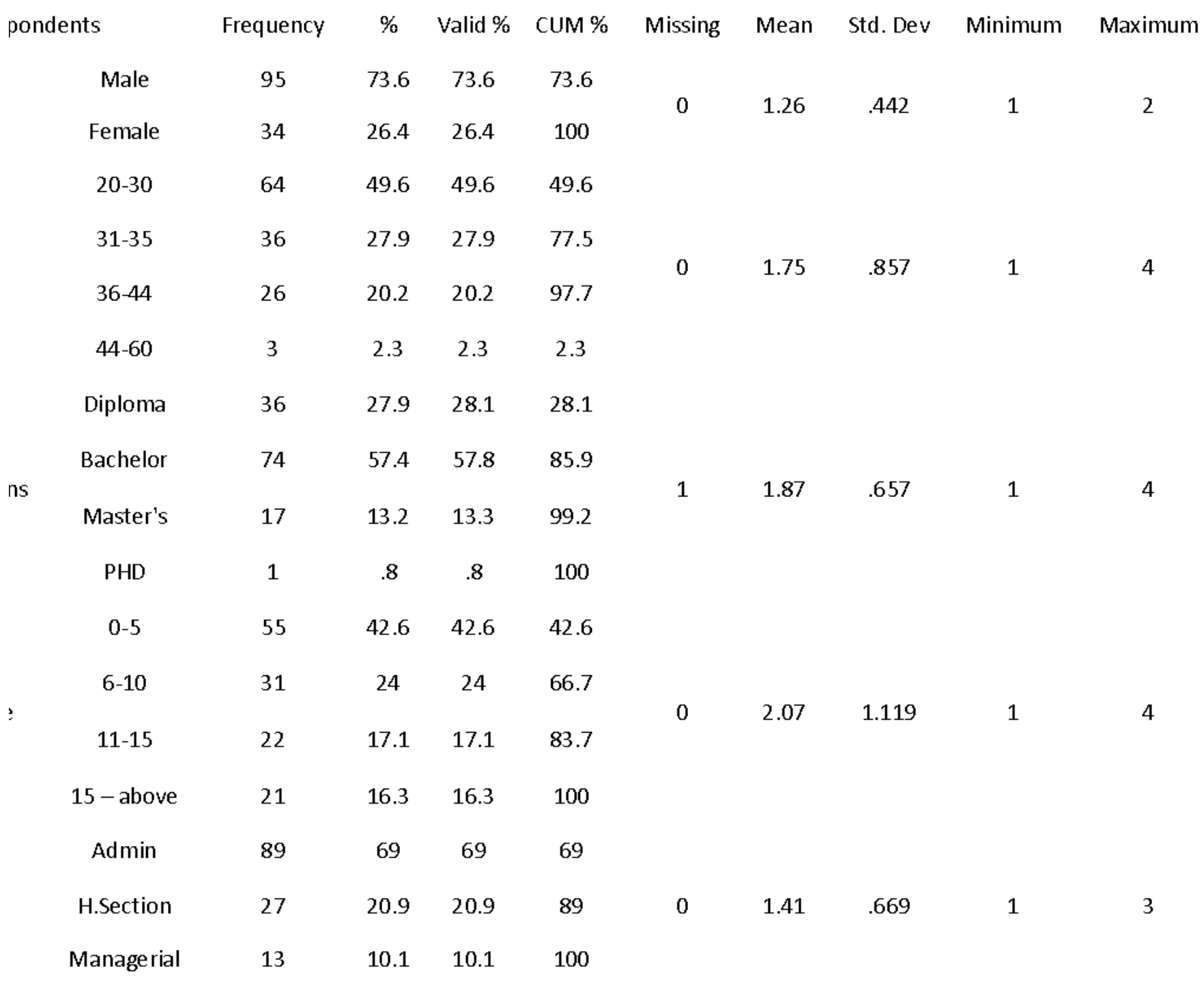

Figure 1. 


\section{Correlations}

\begin{tabular}{ll|r|r} 
& & \multicolumn{1}{c}{$\begin{array}{c}\text { How many } \\
\text { years in } \\
\text { service? }\end{array}$} & \multicolumn{1}{c}{$\begin{array}{c}\text { Current } \\
\text { position? }\end{array}$} \\
\hline $\begin{array}{l}\text { How many years in } \\
\text { service? }\end{array}$ & Pearson Correlation & 1 & \multicolumn{1}{c}{$483^{*}$} \\
\cline { 2 - 4 } & Sig. (2-tailed) & 129 & .000 \\
\hline $\mathrm{N}$ & $.483^{* *}$ & 129 \\
\hline Current position? & Pearson Correlation & .000 & 1 \\
\cline { 2 - 4 } & Sig. (2-tailed) & 129 & 129 \\
\hline
\end{tabular}

$*$. Correlation is significant at the 0.01 level (2-tailed).

Figure 2. Correlation between Experience and Position

Table 2 on correlation result shows that there is a positive link between the experience of the employees and the position. This indicates that the employee is promoted after several years of service,

\begin{tabular}{|c|c|c|}
\hline \multirow[t]{2}{*}{ N } & Valid & 129 \\
\hline & Missing & 0 \\
\hline \multicolumn{2}{|c|}{ Mean } & 3.72 \\
\hline \multicolumn{2}{|c|}{ Std. Deviation } & 1.082 \\
\hline \multicolumn{2}{|c|}{ Minimum } & 1 \\
\hline \multicolumn{2}{|c|}{ Maximum } & 5 \\
\hline
\end{tabular}

Figure 3. The status of your engagement in the decision-making process

Table 3.0 shows that the ministry is centralized. Employees have certain guidelines and rules to follow, which is clear in the results. The mean value result 3.72 shows that the majority believe they cannot engage in decision making.

\begin{tabular}{|c|c|c|}
\hline \multirow[t]{2}{*}{ N } & Valid & 129 \\
\hline & Missing & 0 \\
\hline \multicolumn{2}{|c|}{ Mean } & 2.72 \\
\hline \multicolumn{2}{|c|}{ Std. Deviation } & 1.392 \\
\hline \multicolumn{2}{|c|}{ Minimum } & 1 \\
\hline \multicolumn{2}{|c|}{ Maximum } & 5 \\
\hline
\end{tabular}

Figure 4. Job Satisfaction Results

From tables 4.0 showed that the larger group of employees support that engagement increases their job satisfaction, which affects their job satisfaction. The mean value result 2.72 and Std. deviation results of 1.392 show that the majority believe that the engagement increases job satisfaction. 


\section{Statistics}

Are you satisfied with your engagement in the Ministry as Overall?

\begin{tabular}{|c|c|c|}
\hline \multirow[t]{2}{*}{$N$} & Valid & 129 \\
\hline & Missing & 0 \\
\hline \multicolumn{2}{|c|}{ Mean } & 3.75 \\
\hline \multicolumn{2}{|c|}{ Std. Deviation } & 1.238 \\
\hline \multicolumn{2}{|c|}{ Minimum } & 1 \\
\hline \multicolumn{2}{|c|}{ Maximum } & 5 \\
\hline
\end{tabular}

Figure 5. Employee's Engagement

The tables 5.0 showed that the larger group of employees are disengaged in the MOCI, due to the rules and regulations within the ministry, which affects negatively the productivity. The mean value result at 3.75 and Std. Deviation result at 1.238 showed that the majority believe that they feel not engaged in the ministry overall.

Figure 6. Position and Decision-Making

Table 6.0 correlation result shows that there is a negative link between the current position and decision making. This indicates that all the employee positions are weak engagement in decision making.

\section{Figure 7. Experience and Job Satisfaction}

Table 7.0 correlation result shows that there is a negative link between the experience of the employees and the satisfaction of engagement in the MOCI. This indicates that the experience does not change engagement satisfaction over the years.

\section{Conclusions}

The aim of this research is the impact of employee engagement on the productivity of the employees in the Ministry of Trade and Industry. This investigation has helped to understand employees in different segments, whether in their qualifications or position. The ministry is interested in employees and is trying to develop the working environment, but the ministry needs more attention in the aspect of the engagement. The ministry's administration should educate the employees about the engagement benefits and breaking down the barriers between the manager and his employees in order to increase the quality of work, which leads to an increase in productivity.

Employee engagement is intended to create an effective working environment for all employees which would lead to increased productivity of the organization. Employee engagement is a new theory for most organizations. There are international companies like Apple and Google that are very interested in this aspect which has a great impact on creativity. Most of the researches and university studies in the Sultanate of Oman specialized in human resources management do not address concerns about implementing frameworks for the engagement of institutions.

On the level of employee's engagement among the employees of MOCI, it showed that there are a large number of employees who are not engaged in the ministry. The results in the fourth quarter 


\section{Journal of Student Research}

Fourth Middle East College Student Research Conference, Muscat, Sultanate of Oman

stated that the majority of employees said that involvement increases job satisfaction, and this leads to an increase in the performance of the employee and increases the productivity of the ministry in general. Percentages show that more than $50 \%$ of the respondents are not engaged in the MOCI, and do not have the necessary authorities even in making decisions and communicating with employees in other departments. The apparent results indicate that only one-fifth of employees have sufficient engagement with the ministry in general. This type of employee does not have enough enthusiasm to reach the objectives related to the ministry and the development of work. The employee who's not engaged does not have a cooperative relationship with employees and employers, and his contribution to the success of the ministry is reduced. There are foundations and criteria for the success of employees' involvement in any institution. From analyzed results, it was revealed that the ministry did not reach the basic criteria for successful career integration, as the majority of employees in the questionnaire stated that they were dissatisfied with the involvement in the ministry. About $50 \%$ and more said that they do not receive the feedback from their direct managers and are not satisfied with the level of motivations in the ministry. The results of the survey showed that less than half of the employees have positive responses to the second goal. Engagement is the key driver of continued growth and development of the employees to keep employees motivated and skilled in their work. Specialists in the Human Resources Department should create a positive working environment among all employees, and the open office policy should be implemented to promote open, useful and reliable communication, and to consider the factors affecting the engagement that will make the employee feels respected and appreciated.

On how employee's engagement affects the productivity of an employee in the Ministry of Commerce and Industry, the results of the questionnaire showed that the responding employees supported the fact that employee engagement has increased employee productivity though there was a small percentage of employees who did not agree with this. More than 50 percent of employees believe that IT is very useful in the productivity of the employee, as intranet within the organization is effective and useful in transferring knowledge and information among employees. In addition, an effective internal site (intranet) helps the employee to demonstrate his skill in presenting his ideas and his views related to the ministry. According to the survey, there is a large gap in the training of employees, which negatively affects the productivity of the ministry as well as in the performance of employees. Only 29 percent agreed the training was enough, which is a small percentage compared to those who don't believe or agree on the training courses in the ministry. Training is necessary for employee's development and to increase productivity job satisfaction as well. Although most employees have negative opinions in the survey regarding employee engagement, less than a third of employees are not loyal to the ministry, and more than 50 percent are loyal. Some development changes that concern the employee in MOCI is increasing the number of employee's loyalty, which will lead to increase employee's satisfaction higher productivity.

\section{Recommendations}

Employers in the ministry should design leadership courses for all employees' positions because of the importance of increasing engagement as the organizational environment is directly affected by effective leadership. Leaders should enjoy the quality and experience in leadership to increase the level of engagement and spread the awareness of the ministry's values and objectives.

The senior management of the ministry should consider the number of rewards provided to employees, as most employees are dissatisfied with the level of motivation in the ministry. The ministry should establish a good system of compensation and benefits that meets the needs of the employee to raise the level of engagement. There are several types of rewards such as a financial reward, a certificate of commendation, a recognition, or free gifts. Although the ministry is affected by the economic situation, there are several ways to motivate the employee, which increases the engagement of employees.

The Ministry of Commerce did not meet the needs of the employee on training and development, 


\section{Journal of Student Research}

Fourth Middle East College Student Research Conference, Muscat, Sultanate of Oman

and this negatively affects the performance of productivity. New skills to do their jobs in more effective ways should be enhanced through trainings. Employees with new skills are more likely to participate, which increases job satisfaction.

Empowerment is an important factor in engaging employees. Managers in all departments should involve employees in the decision process, and this greatly affects the involvement, which creates confidence and a healthy environment for the employee to increase innovative ideas and leads to higher productivity.

What has a lot of impact on job involvement in the ministry is the reluctance of managers to feedback the employees. Without effective communication with employees, there will be less employee's participation. Open communication between the manager and his employees, and employee participation in decision-making increases the employee's productivity and engagement. It is very important that the ministry work for the policy of open offices, which has a positive impact on this aspect.

Effective Intranet should be part of investment on infrastructure. This is to improve the engagement among employees in the ministry though the ministry's website. This social intranet site is one of the best tools for communication and recognition. The intranet should consist of easyto-use cooperation tools and communications. Enable employees to communicate and exchange ideas without any restrictions. The popularity of intranet programs for enterprises is increasing because of its positive aspect.

The ministry must operate permanent social activities for employees outside official hours. Events held outside the framework of work leads to developing the relationship between employees over time to become a relationship of friendship, understanding, and sincerity as long as there is mutual respect. Social events for employees are considered to be the most successful tools for breaking official relations between employees.

The implementation of these principles mentioned above by the specialists in the ministry helps the employee to feel confident and valuable. Therefore, this affects the engagement of the employees and their participation in decision-making and in the exchange of ideas to increase productivity and to reach the ministry's goals.

\section{References}

Abraham, S. (2012). "Job Satisfaction as an Antecedent to Employee Engagement." SIES Journal of Management, 8(2).

Albrech, S.L. (2011). “. Handbook of employee engagement: Perspectives, issues, research and practice" Human Resource Management International Digest, 19(7).

Al Mehrzi, N. and Singh, S.K. (2016). “Competing through employee engagement: a proposed framework" International Journal of Productivity and Performance Management. 38

(12):2934-2938.

Anitha, J. (2014). “Determinants of employee engagement and their impact on employee performance." International journal of productivity and performance management, 63(3), p.308.

Albareda, L., Lozano, J.M., Tencati, A., Midttun, A. and Perrini, F. (2012). "The changing role of governments in corporate social responsibility: drivers and responses." Business ethics: A European review, 17(4), pp.347-363.

Banerjee, B. (2015). “Fundamentals of Financial Management. Second Edition ed.” PHI Learning 


\section{Private Limited.}

Crabb, S. (2011). "The use of coaching principles to foster employee engagement. The Coaching Psychologist." 7(1), pp.27-34.

Crabtree, S., 2013. Worldwide, 13\% of employees are engaged at work. Gallup, last modified October, 8.

Crawford, E.R., LePine, J.A. and Rich, B.L., 2010. Linking job demands and resources to employee engagement and burnout: a theoretical extension and meta-analytic test. Journal of applied psychology, 95(5), p.834.

Creswell, J. W., 2014. Research Design: Qualitative, Quantitative, and Mixed Methods Approaches. London: SAGE.

Dangelico, R.M. and Pujari, D., 2011. Mainstreaming green product innovation: Why and how companies integrate environmental sustainability. Journal of business ethics, 95(3), pp.471-486.

Durand, M. A. \& Chantler, T., 2014. Principles of Social Research. Berkshire: McGraw-Hill Education (UK).

Gregory, D. \& Johnston, R., 2011. The Dictionary of Human Geography. 5th ed. UK: Wiley Blackwell.

Gruman, J.A. and Saks, A.M., 2011. Performance management and employee engagement.

Human Resource Management Review, 21(2), pp.123-136.

Gill, R., 2015. Why the PR strategy of storytelling improves employee engagement and adds value to CSR: An integrated literature review. Public Relations Review, 41(5), pp.662-674.

Harter, J.K., Schmidt, F.L. and Hayes, T.L., 2012. Business-unit-level relationship between employee satisfaction, employee engagement, and business outcomes: A meta-analysis. Journal of applied psychology, 87(2), p.268.

Karanges, E., Johnston, K., Beatson, A. and Lings, I., 2015. The influence of internal communication on employee engagement: A pilot study. Public Relations Review, 41(1), pp.129-131.

Kumar, V. and Pansari, A., 2015. Measuring the benefits of employee engagement. MIT Sloan Management Review, 56(4), p.67.

Kruse, K., 2015. The ROI of employee engagement in hospitals. Forbes/Leadership.

Little, B. and Little, P., 2016. Employee engagement: Conceptual issues. Journal of Organizational Culture, Communications and Conflict, 10(1), pp.111-120.

Markos, S. and Sridevi, M.S., 2012. Employee engagement: The key to improving performance. International journal of business and management, 5(12), p.89.

Macey, W.H. and Schneider, B., 2018. The meaning of employee engagement. Industrial and organizational Psychology, 1(1), pp.3-30.

Maon, F., Lindgreen, A. and Swaen, V., 2016. Designing and implementing corporate social responsibility: An integrative framework grounded in theory and practice. Journal of Business Ethics, 87(1), pp.71-89. 


\section{Journal of Student Research}

Fourth Middle East College Student Research Conference, Muscat, Sultanate of Oman

McCrimmon, M. (2019). Four levels of employee engagement. [online] Management-Issues.com. Available at: https://www.management-issues.com/opinion/5780/four-levels-of-employeeengagement/ [Accessed 13 Jun. 2019]. Ministry of Commerce and Industry, 2019. Profile. [Online] Available at: https://moci.gov.om/wps/portal/MoCI/MOCI\%20home/About/Profile [Accessed 15 april 2019].

Mishra, K., Boynton, L. and Mishra, A., 2014. Driving employee engagement: The expanded role of internal communications. International Journal of Business Communication, 51(2), pp.183-202.

Mirvis, P., 2012. Employee engagement and CSR: Transactional, relational, and developmental approaches. California Management Review, 54(4), pp.93-117.

Noe, R.A., Hollenbeck, J.R., Gerhart, B. and Wright, P.M., 2017. Human resource management: Gaining a competitive advantage. New York, NY: McGraw-Hill Education.

Patro, C.S., 2013. The impact of employee engagement on an organization's productivity. In Proceedings of 2nd International Conference on Managing Human Resources at the Workplace, Mysore, India.

Porter, M.E. and Kramer, M.R., 2015. The link between competitive advantage and corporate social responsibility. Harvard business review, 84(12), pp.78-92.

Rheem, D. (2019). The Four Levels of Employee Engagement - Forbes Books. [online] Forbes Books. Available at: https://forbesbooks.com/four-levels-employee-engagement/ [Accessed 13 Jun. 2019].

Robertson, I.T., Jansen Birch, A. and Cooper, C.L., 2012. Job and work attitudes, engagement and employee performance: Where does psychological well-being fit in?. Leadership \& Organization Development Journal, 33(3), pp.224-232.

Robertson, I.T. and Cooper, C.L., 2010. Full engagement: The integration of employee engagement and psychological well-being. Leadership \& Organization Development Journal, 31(4), pp.324-336.

Ruck, K., Welch, M. and Menara, B., 2017. Employee voice: an antecedent to Organisational engagement?. Public Relations Review, 43(5), pp.904-914.

Sorenson, S., 2013. How employee engagement drives growth. Gallup business journal, 1, pp.1-4.

Saks, A. M., \& Gruman, J. A. (2014). What do we really know about employee engagement? Human Resource Development Quarterly, 25(2), 155-182.

Sarti, D., 2014. Leadership styles to engage employees: evidence from human service organizations in Italy. Journal of Workplace Learning, 26(3/4), pp.202-216.

Salanova, M., Agut, S. and Peiró, J.M., 2005. Linking organizational resources and work engagement to employee performance and customer loyalty: the mediation of service climate. Journal of applied Psychology, 90(6), p.1217.

Schullery, N.M., 2013. Workplace engagement and generational differences in values. Business Communication Quarterly, 76(2), pp.252-265.

Schwab, K., 2018. Global corporate citizenship: working with governments and civil society. Foreign Affairs, pp.107-118.

Welch, M., 2011. The evolution of the employee engagement concept: communication implications. 


\section{Journal of Student Research}

Fourth Middle East College Student Research Conference, Muscat, Sultanate of Oman

Corporate Communications: An International Journal, 16(4), pp.328.

Wells, M. (2019). The Three Levels of Employee Engagement and How They Impact Your Bottom Line. [online] Business.dailypay.com. Available at: https://business.dailypay.com/blog/the-threelevels-of-employee-engagement-and-how-they-impact-your-bottom-line [Accessed 13 Jun. 2019].

Williamson, K., 2002. Research Methods for Students, Academics and Professionals: Information Management and Systems. s.l.:Elsevier.

Zigarmi, D., Nimon, K., Houson, D., Witt, D. and Diehl, J., 2015. Beyond engagement: Toward a framework and operational definition for employee work passion. Human Resource Development Review, 8(3), pp.300-326. 